\title{
Potential Applications of Nanotechnology in Urological Cancer
}

\author{
Ming-Hui He ${ }^{1}$, Li Chen', Ting Zheng ${ }^{1}$, Yu Tu', Qian He', Hua-Lin Fu', Ju-Chun Lin', \\ Wei Zhang', Gang Shu', Lili He ${ }^{2 *}$ and Zhi-Xiang Yuan ${ }^{1 *}$ \\ ${ }^{1}$ Department of Pharmacy, College of Veterinary Medicine, Sichuan Agricultural University, Chengdu, China, ${ }^{2}$ College of \\ Pharmacy, Southwest Minzu University, Chengdu, China
}

OPEN ACCESS

Edited by:

Qingxin Mu,

University of Washington

United States

Reviewed by:

Gaoxing Su,

Nantong University, China

Weikuan Gu,

University of Tennessee Health Science Center, United States

*Correspondence:

Lili $\mathrm{He}$

lilihes@163.com

Zhi-Xiang Yuan

zhixiang-yuan@hotmail.com

Specialty section:

This article was submitted to

Cancer Molecular Targets

and Therapeutics,

a section of the journal

Frontiers in Pharmacology

Received: 28 April 2018

Accepted: 19 June 2018

Published: 09 July 2018

Citation:

He M-H, Chen L, Zheng T, Tu Y,

He Q, Fu H-L, Lin J-C, Zhang W,

Shu G, He L and Yuan Z-X (2018)

Potential Applications

of Nanotechnology in Urological

Cancer. Front. Pharmacol. 9:745.

doi: 10.3389/fphar.2018.00745
Nowadays, the potential scope of nanotechnology in uro-oncology (cancers of the prostate, bladder, and kidney) is broad, ranging from drug delivery, prevention, and diagnosis to treatment. Novel drug delivery methods using magnetic nanoparticles, gold nanoparticles, and polymeric nanoparticles have been investigated in prostate cancer. Additionally, renal cancer treatment may be profoundly influenced by applications of nanotechnology principles. Various nanoparticle-based strategies for kidney cancer therapy have been proposed. Partly due to the dilution of drug concentrations by urine production, causing inadequate drug delivery to tumor cells in the treatment of bladder cancer, various multifunctional bladder-targeted nanoparticles have been developed to enhance therapeutic efficiency. In each of these cancer research fields, nanotechnology has shown several advantages over widely used traditional methods. Different types of nanoparticles improve the solubility of poorly soluble drugs, and multifunctional nanoparticles have good specificity toward prostate, renal, and bladder cancer. Moreover, nanotechnology can also combine with other novel technologies to further enhance effectivity. As our understanding of nanotechnologies grows, additional opportunities to improve the diagnosis and treatment of urological cancer are excepted to arise. In this review, we focus on nanotechnologies with potential applications in urological cancer therapy and highlight clinical areas that would benefit from nanoparticle therapy.

\section{Keywords: nanotechnology, urological cancer, nanoparticles, diagnosis, therapy}

\section{INTRODUCTION}

Urological cancers, which include cancers of the prostate, kidneys, and bladder, are an international public health problem. Minimally invasive surgical approaches are now the most common treatments for urological malignancies, although open radical nephrectomy was the most common treatment for non-metastasized lesions in the 1980s. Most prostate cancers, regardless of tumor size, are treated by laparoscopic nephrectomy (Rassweiler et al., 2013). In contrast, bladder cancer $(\mathrm{BCa})$ is treated with different approaches depending on the stage of the cancer. Transurethral resection of bladder tumors (TUR-BT) is the first strategy for curing non-invasive bladder tumors, and Bacillus Cal-mette-Guérin (BCG) and chemotherapeutic agents are also widely used (Chen et al., 2015a). Many novel techniques for use in urological cancer have been developed in the past decade. For example, focal ablation using cryotherapy or radiofrequency (RF) is becoming more popular for small renal masses (Park et al., 2006; Lusch et al., 2013), and new methods, 
such as real-time peripheral temperature monitoring, are involved in establishing the efficacy of RF ablation (Leveillee et al., 2013). Similarly, in the treatment of prostate tumors, highintensity focused ultrasound, a minimally invasive therapy, can be accurately targeted to a portion of the prostate gland and has been widely used for the treatment of prostate cancer (Crouzet et al., 2014). However, these traditional surgical therapies sometimes lack accuracy and have a high risk of complications, including tumor relapse (Kondylis et al., 2000). Moreover, the use of chemical agents may cause negative side effects in normal cells and could be associated with relapse.

Imaging of tumors can facilitate early diagnosis and influence patients' treatment decisions. Computed tomography (CT), Positron emission tomography (PET), and magnetic resonance imaging (MRI) are traditionally used for detection of non-invasive malignancies. However, these traditional approaches have limited sensitivity and ability to provide specific and functional information on the disease (Wang et al., 2008).

Nanoparticles (NPs, size in nanometer range) are novel materials used that were initially used for invention of the scanning probe microscopy and the discovery of molecular structures (Menter et al., 2014). Different manufacturing methods and materials have enabled the production of NPs with various shapes and sizes. One nanometer $\left(10^{-9} \mathrm{~m}\right)$ is the scale at which most biological molecules operate inside living cells; thus, NPs may have many applications in the field of medicine. NPs can accumulate in tumor tissues via the enhanced permeability and retention (EPR) effect; under certain circumstances, typically for tumors, the endothelial lining of the blood vessel wall becomes more permeable than in the normal state, allowing NPs to enter tumors (Ojha et al., 2017). NPs can be used for encapsulation of poorly soluble drugs, protection of therapeutic molecules, modification of their blood circulation and tissue distribution profiles, and facilitation of combination regimens commonly used in cancer therapy (Bertrand et al., 2014). Many types of NPs, including liposomes and other lipid-based carriers (such as lipid emulsions and lipid-drug complexes), polymerdrug conjugates, polymer microspheres, micelles, and various ligand-targeted products (such as immunoconjugates), are under various stages of development as drug delivery systems (Wang et al., 2008). Additionally, NPs play an important role in cancer diagnosis, and may have applications in the treatment of tumors (Figure 1). Contemporary cancer therapy, particularly with respect to drug delivery, has evolved from traditional methodology to new technology. Thus, nanotechnology-based
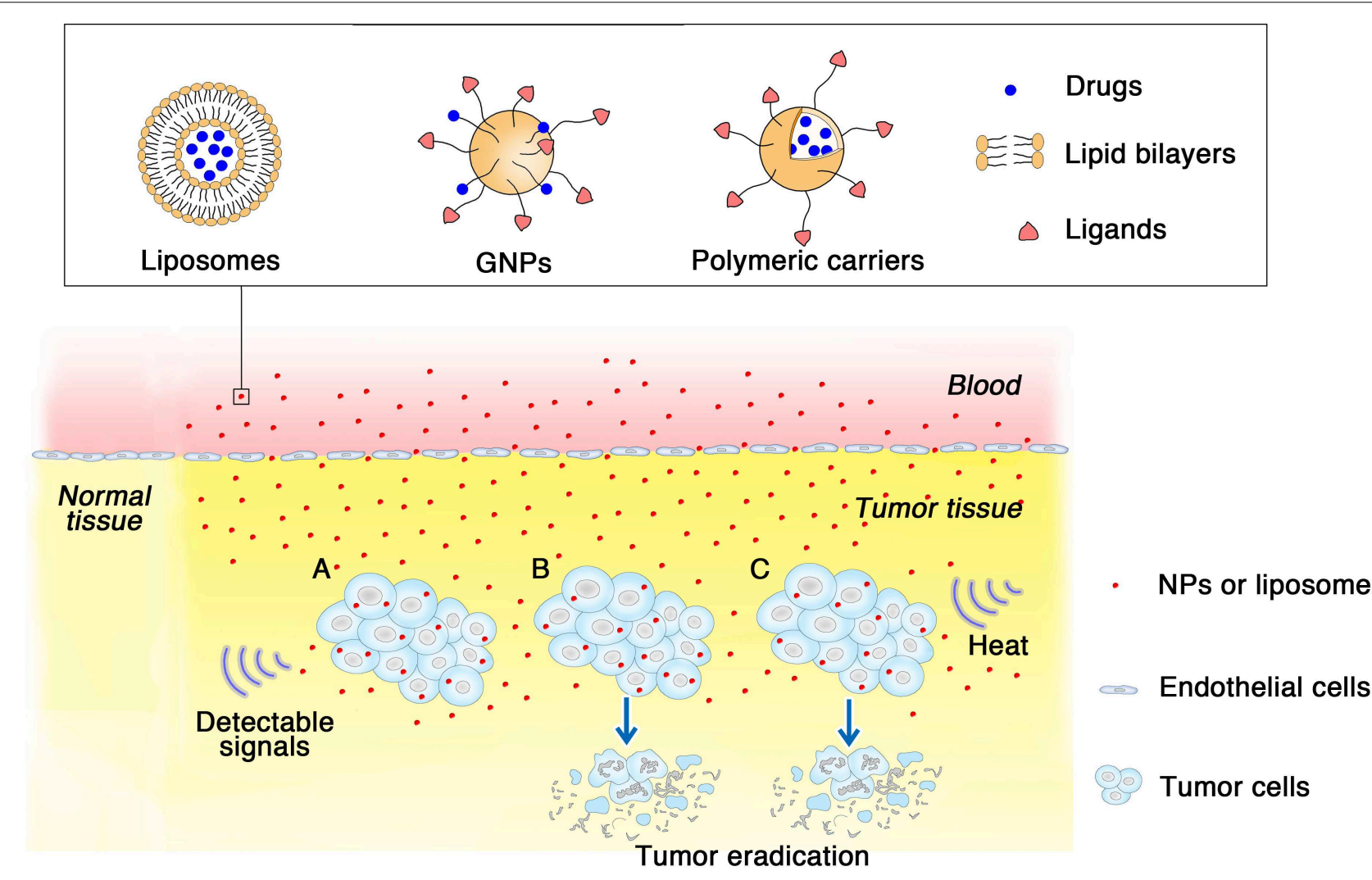

FIGURE 1 | How different kinds of NPs applied in urological cancer diagnosis and therapeutics. Three types of NPs are listed for examples, liposomes, GNPs and polymeric NPs. With specific ligands modified on the surface, NPs show specifia targeting to the tumor cells via EPR effect. (A) NPs as imaging agents gather around tumor tissues then send and amplify detectable signals which are received subsequently. (B) NPs loaded with cytotoxic drugs arrive at tumor tissue, and then lead to tumor eradication. (C) In hyperthermia therapy, NPs absorbing heat energy induce a high temperature, causing focal cell death and preserve the circumambient normal tissue. 
combination drug delivery to tumor tissues has emerged as a potential effective strategy for cancer therapy.

Nanotechnology has shown several advantages over widely used traditional methods. Different types of NPs improve the solubility of poorly soluble drugs and multifunctional NPs have good specificity toward prostate, renal and bladder cancers. Moreover, nanotechnology can also combine with other upcoming technologies and enhance the effectivity. As our understanding of nanotechnologies grows, opportunities to improve the diagnosis and treatment methods for urological cancer have also increased. In this review, we focus on nanotechnologies with potential applications in prostate, renal, bladder, and other urologic cancer. In each of these fields, we discuss various NP-based strategies for diagnosis as well as treatment. In addition, we provide future perspectives to highlight the requirement for further studies.

\section{NANOTECHNOLOGY IN PROSTATE CANCER}

Prostate cancer is one of the leading causes of cancer-related deaths among men (Siegel et al., 2018). Chemotherapeutic agents, such as docetaxel and paclitaxel, which are widely used for the treatment of prostate cancer, are not selective to cancerous tissues and can cause injury to normal tissues, leading to a low therapeutic index and even increasing drug resistance. Consequently, novel approaches are urgently needed for the development of improved therapeutic options for the management of prostate cancer, particularly with regard to inhibition of the proliferation of precancerous and malignant lesions and/or to improvement of the effectiveness of conventional chemotherapeutic agents. NP technology is being widely used in prostate cancer, both in diagnostic and therapeutic fields, providing a promising strategy for drug delivery; such approaches with NP technology can make up for the lack of specificity of traditional therapy. Emerging NP technologies use for imaging and therapy in prostate cancer will be discussed in this section, with the aim of highlighting novel advances in NP technology for applications in prostate cancer.

\section{Imaging in Prostate Cancer}

Magnetic resonance imaging and CT are two of the most critical and widely used methods for disease staging and diagnosis. In both methods, magnetic NPs (MNPs) can provide an encouraging solution as precursors for targeted contrast agents. MNPs in the form of superparamagnetic iron oxides (SPIOs) and ultrasmall SPIOs (USPIOs) have already been applied in clinical trials, with several advantages, including long blood-retention time, biocompatibility, and minimal biotoxicity (Feldman et al., 2008; Sun et al., 2008). Huang colleagues formulated new cationic lipid NPs containing SPIOs (L-SPIOs) to solve the problem of low efficiency of direct loading into cells and the cytotoxicity of SPIOs. The study used PC3 prostate cancer cells to test the efficiency of cellular uptake of these L-SPIOs, and the results showed that these L-SPIOs, which exhibited high loading efficiency, low cytotoxicity, and long-term imaging signals, are versatile image probes for cell tracking (Huang et al., 2009). Other metallic materials are also being developed. For example, Ghasemian et al. (2015) recently showed the potential applications of cobalt zinc ferrite NPs (CZF-MNPs) as a T2 contrast agent. In vitro, dimercaptosuccinic acid (DMSA)-coated or uncoated CZF-MNPs were incubated with PC3 or DU145 prostate cancer cells for $2 \mathrm{~h}$ at room temperature. Using a T2weighted MRI system, researchers found that both uncoated and coated NPs were imported in PC3 and DU145 cells, resulting in a dramatic signal intensity reduction. In addition, the enhanced intensity observed using CZF-MNPs was similar to that of an equal amount of DMSA-coated CZF-MNPs, indicating that these particles were both suitable for T2 contrast enhancement (Ghasemian et al., 2015).

Photoacoustic imaging (PAI) is an emerging non-invasive imaging modality that combines the spectral selectivity of molecular excitation by laser light with the high resolution of ultrasound imaging. Some types of NPs, particularly gold NPs (GNPs), are designed for high photoacoustic contrast based on surface plasmon resonance (SPR) to enhance absorption (Agarwal et al., 2007; Yang et al., 2009). In addition to its apparent clinical safety and tolerability due to its physical inertness, gold can be used to synthesize NPs with very precise sizes, shapes, and surface chemistries at the nanoscale using simple techniques and relatively inexpensive reagents (Daniel and Astruc, 2004). A study demonstrated that PAI based on a targeted gold nanorod contrast agent could provide a clear anatomical view with targeted tissue highlighted in a contrasting color in LNCaP prostate cancer cells (Agarwal et al., 2007). The gold nanorods could be also used for detection of other lesions. Currently, GNPs are being used in several clinical trials as radiopaque markers that can be implanted into patients with prostate cancer for image-guided therapy (Kliton et al., 2014; Jorgo et al., 2017). The results showed that implantation had no apparent side effects, such as fever or infection, and none of the patients required analgesics after implantation, suggesting that GNPs could be potential imaging agents for use in clinic applications.

Molecular targets of prostate cancer, including prostatespecific antigen (PSA), prostate-specific membrane antigen (PSMA), and prostate cancer lipid antigen, are products of prostate cells and are used as potential NP targets (Cheng et al., 2012; Sanna and Sechi, 2012). Normal PSA immunoassays are often not able to detect PSA in the serum after radical prostatectomy due to the low sensitivity of the assays. However, using an extremely sensitive nanotechnology-based tool known as the "bio-barcode" system, the sensitivity of immunoassays has increased by 300-fold compared with that of commercial immunoassays, and the results of clinical studies have also confirmed these findings. This ultrasensitive technology is based on GNP probes decorated with DNA and antibodies that can recognize and bind to PSA when presenting at extremely low levels in blood samples (Thaxton et al., 2009). GNPs have also shown great efficiency and robustness as probes for sensing ultralow levels of PSA in patient serum samples. The limit of detection of the probe for PSA reached $32 \mathrm{fg} / \mathrm{mL}$, which is more than two orders of magnitude lower than that of the conventional fluorescence probe and even lower than that of the 
GNP bio-barcode assay (330 fg/mL) (Liu et al., 2013). Many other nanomaterials, such as carbon nanotubes (Patra et al., 2015) and quantum dots (Brazhnik et al., 2015), which can detect PSA at low levels and do not harm the body or normal cells, are also being applied as sensors for detection of PSA.

\section{Therapeutics in Prostate Cancer}

In the clinical setting, prostate cancer can roughly be classified as localized, expansively localized, or metastatic. Localized cancer is thought to be curable, whereas metastatic cancer leads to androgen-independent progression and death within a few years (Salvador-Morales et al., 2009). Traditional methods include chemotherapy using chemopreventive agents and radical prostatectomy, and new methods, such as cryosurgery, radiation with conformal external beam radiation, and brachytherapy, have also recently emerged. However, current treatments for prostate cancer are not sufficiently reliable for targeting of neoplastic cells without damaging normal cells. Finding new ways to overcome the disadvantages of conventional therapy methods is necessary, and nanotechnology may provide one such relevant approach. Table 1 provides an overview of NPs that are promising for prostate cancer treatment.

Many studies have shown that natural products are potent chemopreventive agents in prostate cancer due to their considerable efficacy against tumor cells and low toxicity (Jeong et al., 2011; Sanna et al., 2013; Kumar et al., 2015). For example, a recent study on chrysophanol, a natural compound extracted from plants of the genus Rheum, using GNPs as carriers to improve its bioavailability and water solubility successfully showed that chrysophanol suppresses human prostate cancer progression at the molecular level (Lu et al., 2017). Molecular targeted cancer therapy mediated by NPs is a promising strategy to overcome the non-specific biodistribution and therapeutic index of conventional chemotherapeutic drugs. Importantly, PSMA-modified NPs have been developed as a powerful treatment for prostate cancer. By conjugating PSMA to NPs, the functional particles can have good selectivity and target drugs, such as natural products or other chemotherapeutic drugs, to diseased tissue. For example, a natural product isolated from green tea, (-)-epigallocatechin 3-gallate (EGCG) shows potent chemopreventive effects in in vitro and in vivo models of prostate cancer, and several clinical trials have been conducted to determine the ability of green tea extracts to prevent the development and progression of prostate cancer (Stuart et al., 2006). A recent study showed that EGCG may be beneficial in the early stages of prostate cancer. Sanna colleagues designed biocompatible polymeric EGCG-encapsulated NPs modified with PSMA to selectively deliver EGCG to prostate cancer cells. Experiments in vitro demonstrated that these novel NPs could lead to increased antiproliferative activity toward PSMA-positive prostate cancer cells, without affecting normal cell viability (Sanna et al., 2011). Similarly, by conjugating GNPs with an ONT-hybridized, PSMA-specific aptamer, a GC-rich duplex acting as a loading site for doxorubicin was formed. Kim et al. (2010) established multifunctional NPs for both prostate imaging and treatment. This novel NP bioconjugate not only enabled

TABLE 1 | Overview of NPs designed for urological cancer treatments.

\begin{tabular}{|c|c|c|c|}
\hline Cancer types & Treatment strategies & Applied NPs & Reference \\
\hline \multirow[t]{5}{*}{ Prostate cancer } & Chemotherapy & GNPs loaded with chrysophanol & Lu et al., 2017 \\
\hline & & $\begin{array}{l}\text { EGCG-encapsulated polymeric NPs modified } \\
\text { with PSMA }\end{array}$ & Sanna et al., 2011 \\
\hline & Gene therapy & Polymeric NPs loaded with GS25 & Voruganti et al., 2015 \\
\hline & & GNPs loaded with miRNA & Ekin et al., 2014 \\
\hline & Thermal therapy & MNPs and GNPs & Johannsen et al., 2007a, 2010 \\
\hline \multirow[t]{7}{*}{ Renal cancer } & Targeted therapy & $\begin{array}{l}\text { Sorafenib-loaded PLGA NPs, DPPC liposomes } \\
\text { and HMC-coated DPPC liposomes }\end{array}$ & Liu et al., 2015a,b \\
\hline & Gene therapy & FA-PEAs:VHL complexes & Sudimack and Lee, 2000 \\
\hline & Thermal therapy & PEGylated gold nanoshells & Pannerec-Varna et al., 2013 \\
\hline & & MWCNTS & Burke et al., 2009 \\
\hline & PDT & GNPs with radiofrequency radiation & Nikzad et al., 2017 \\
\hline & Targeted therapy & Cuprous oxide nanoparticles & Yang et al., 2017 \\
\hline & & Superparamagnetic-like particles & Leulmi et al., 2015 \\
\hline \multirow[t]{7}{*}{ Bladder cancer } & Immunotherapy & Liposomes encapsulating BCG's CWS & Nakamura et al., 2014 \\
\hline & Gene therapy & $\begin{array}{l}\text { PEGylated cationic liposome carriers (PCat, } \\
\text { PPCat) and modified PLGA NPs delivering } \\
\text { siSurvivin }\end{array}$ & Martin et al., 2014; Cui et al., 2015 \\
\hline & Targeted therapy & PLGA NPs loaded with belinostat & Martin et al., 2013 \\
\hline & Chemotherapy & Paclitaxel-loaded protein NPs & Lu et al., 2011; McKiernan et al., 2011 \\
\hline & PTा & GNPs & Chen et al., 2015b \\
\hline & & $\begin{array}{l}\text { Silica-Au nanoshells, Au/Ag nanospheres, and } \\
\text { Au nanorods modified with tumor targeting } \\
\text { antibodies }\end{array}$ & Juarranz et al., 2008; Cheng et al., 2009 \\
\hline & & NP-AAG & Long et al., 2018 \\
\hline
\end{tabular}


visualization of target-specific binding by silver staining and clinical CT scanning but also efficiently induced cell death in prostate cancer cells (Kim et al., 2010).

Gene therapy is an extensive method used for the treatment of prostate cancer. Generally, there are four main strategies for gene therapy: tumor-suppressor therapy, suicide gene therapy, immunomodulatory gene therapy, and anti-oncogene therapy. However, none of these approaches can be applied alone as therapeutic treatment due to the low specificity of cell targeting and inefficient gene transfer and expression (Djavan and Nasu, 2001). NPs are widely used in anti-oncogene therapy to overcome these problems, and many studies have used nanodelivery systems to enhance the activities of oncogene inhibitors. For example, 25- $\mathrm{OCH}_{3}-\mathrm{PPD}$ (GS25) is a natural inhibitor of the MDM2 oncogene, which can be amplified and/or overexpressed in prostate cancer. When loaded with polyethylene glycol-poly(lactic-co-glycolic acid) NPs, GS25 showed enhanced anticancer efficacy in vitro and in vivo without inducing toxicity and exhibited improved uptake in cancer cells (Voruganti et al., 2015). MicroRNAs are commonly used as tools in gene cloning to induce post-transcriptional gene silencing. Some studies have shown that GNP-based nanocarriers (Ekin et al., 2014) and prostate cancer-targeted polyarginine-disulfide linked polyetherimide (PEI) nanocarriers (Zhang et al., 2015) can promote miR-145 delivery into prostate tumors.

Magnetic fluid hyperthermia (MFH) is another promising method of prostate cancer treatment using biocompatible MNPs injected directly into superficial or deep-seated tumors and consecutively heated in an alternating magnetic field (Johannsen et al., 2010). Because tumor cells have a lower heat tolerance than normal cells, increasing the temperature to $40-43^{\circ} \mathrm{C}$ by hyperthermia (HT) can lead to tumor cell necrosis and apoptosis. MNPs play an important role in this novel therapy due to the excellent power absorption capabilities of magnetic fluids in a magnetic field (Jordan et al., 1993). A prospective clinical study investigated $\mathrm{MFH}$ as a monotherapy used in patients with locally recurrent prostate cancer and showed that this approach was feasible and well-tolerated; additionally, deposition of NPs in the prostate was highly durable (Johannsen et al., 2005a, 2007a,b). Recent studies have shown that HT combined with radiotherapy (RT) may be effective for the treatment of prostate cancer (Hurwitz et al., 2011; Datta et al., 2015), and MFH can effectively enhance RT, leading to significant growth inhibition in mouse models of human prostate cancer (Johannsen et al., 2005b; Attaluri et al., 2015).

In addition to MNPs, GNPs have also shown several advantages in HT therapy, including good biocompatibility. In a study of the influence of different physical characteristics (shape, size, surface properties, and concentration) of GNPs on cellular uptake, adsorption of proteins, and toxicity in PC3 human prostate cancer cells, size-dependent uptake and negligible toxicity were observed (Arnida et al., 2010). Similar to HT therapy, thermal ablative energy causes necrosis of target tissues by inducing a high temperature, leading to focal cell death and preserving the circumambient normal tissue (Sanna et al., 2011). Studies using systemically administered non-targeted NIR-activatable gold nanoshells for thermal ablation of tumors date back to the early 21 st century; however, very few reports have documented its utility in the treatment of prostate cancer (Krishnan et al., 2010). Stern et al. (2007) studied gold nanoshellmediated photothermal ablation of prostate cancer cells and found complete loss of cell viability while maintaining intact cellular morphology. A subsequent study evaluated the efficacy of laser-activated gold nanoshell thermal ablation for eradicating prostate cancer in vivo and compared the therapeutic efficacies of two doses of gold nanoshells ( 7 and $8.5 \mu \mathrm{L} / \mathrm{g}$ body weight). The results demonstrated that the low concentration of gold nanoshells arrested cell growth, whereas the high concentration of gold nanoshells dramatically decreased tumor volume (93\% tumor necrosis and regression) within just 1 week (Stern et al., 2008). Other applications of GNPs are also being investigated. For example, genetically modified phages (with both gold-binding peptide and PC3-binding peptide) were induced to attract GNPs to form a cluster, enabling stable maintenance of cell-targeting functionality and killing of the targeted prostate cancer cells within a short time. The prostate cancer cells were killed more efficiently and selectively than non-GNP-treated cells (Oh et al., 2015).

\section{NANOTECHNOLOGY IN RENAL CANCER}

Renal cell carcinoma (RCC) is not a single entity, but includes a group of tumors with a highly heterogeneous epithelium originating from the renal tubules. There are three dominant histopathological types of RCC: clear cell (65\%), papillary (1520\%), and chromophobe (5\%) (Bouchelouche, 2016; Yuan et al., 2016). RCC is the third most common urinary system cancer, with an incidence rate of about 5-10 cases per 100,000 people, and accounts for $2-3 \%$ of all malignant tumors (Xu et al., 2010). Although chemotherapy is one of the main modes of cancer treatment, its effectiveness is limited by drug resistance. For example, sunitinib is currently the standard first-line treatment for advanced RCC, and patient inevitably become resistant to sunitinib treatment (Yang et al., 2017). In addition, the clinical outcomes in patients with RCC remain poor. Therefore, rapid development of nanotechnologies may improve therapeutic strategies for the diagnosis and treatment of RCC (Yang et al., 2017).

\section{Imaging in Renal Cancer}

Pinpoint imaging of RCC is one of the main issues for the diagnosis, staging, and clinical treatment of patients (Bouchelouche, 2016). In current oncology, a series of NPs for diagnostic assays have been developed, and these NPs are commonly used as contrast agents for MRI and CT imaging (Sanna et al., 2011; Williams et al., 2016).

Lu et al. (2014) conjugated the monoclonal antibody G250 and SPIO into molecular MRI probes for the in vitro detection of clear cell RCC (ccRCC) using a 3.0-Tesla MRI. An in vitro MRI study of ccRCC and control cells confirmed that the fabricated mAb G250-SPIO nanoprobe could be used as a specific marker for ccRCC cells (Lu et al., 2014). Moreover, the nanoprobe could be easily conjugated with other antitumor drugs and 
imaging materials to achieve multimodal imaging and diagnostic treatment integration. For example, the combination of Cy5labeled glycosylated bleomycin (Yu et al., 2013; Bhattacharya et al., 2014) and the nanoprobe may provide a new direction for the design of novel tumor imaging and therapeutic agents. Besides, GNPs or quantum dots as imaging materials (Mieszawska et al., 2013; Zrazhevskiy and Gao, 2013) could also be developed with the mAb G250 nanoprobe to promote highly multiplexed parallel staining, resulting preferable imaging.

Many studies have demonstrated that the diagnosis of RCC can be performed by multifarious NP imaging. However, urologists are often faced with imaging dilemmas, including lack of definitive answers in clinical practice during the diagnosis of RCC histology (Farber et al., 2015). In addition, whether contrast-enhanced imaging of RCC has any side effects in patients is worth considering. We expect to see a growing number of nanotechnologies to fill technological gaps in the diagnosis and treatments of RCC.

\section{Therapeutics in Renal Cancer}

Nanomedicine strategies may be more effective than other strategies for controlling drug delivery and release. Due to the high porosity of the tumor vasculature, impaired lymphatic drainage, known as the enhanced permeability and retention effect, or the high affinity of the NPs for markers specifically expressed on cancer cells can result in easy accumulation at the tumor site. Therapeutic nanotechnology focuses on the utilization of photothermal-based ablative energy, which is sent to the targeted lesion by activating various types of NPs (Sanna et al., 2011). Typical nanomedicine delivery vehicles include liposomes, polymeric NPs, nanoshells, and MNPs (Table 1).

Many preclinical studies have examined liposomal strategies for drug delivery in RCC; however, only a few clinical studies have been conducted (Williams et al., 2016). Polyethylene glycol (PEG)-ylated-liposomal doxorubicin (Doxil) was used for the treatment of patients with intractable RCC in a phase II clinical trial. The results showed that Doxil was ineffective in patients with RCC, although slightly toxic side effects were observed (Skubitz, 2002). Liu et al. (2015a,b) systemically estimated the in vitro applicabilities of several drugs as delivery systems for the treatment of RCC, including sorafenib-loaded poly(lactic-co-glycolic acid) (PLGA) NPs, 1, 2-dipalmitoyl-sn-glycero-3-phosphocholine (DPPC) liposomes, and hydrophobically modified chitosan (HMC)-coated DPPC liposomes. The results showed that sorafenib-loaded PLGA NPs and HMC-coated DPPC liposomes could apparently kill more RCC cells than sorafenib alone at lower concentrations. Moreover, XL184 liposomes counteracted tumor activity by inhibiting the phosphorylation of Met, AKT, and mitogenactivated protein kinase pathways in RCC cells (Kulkarni et al., 2016). The above studies indicated that liposomes may have applications in multikinase pathway inhibition as a prospective treatment for RCC.

Folic acid-modified poly( $\varepsilon$-caprolactone)-pluronic-poly ( $\varepsilon$-caprolactone) grafted isophorone diidocyanate-PEI (FAPEAs) was developed as a low-toxicity carrier to transfer Von Hippel-Lindau (VHL) plasmids to treat mice in an RCC model.
Johnson et al. (2010) found that the mean tumor volume in FA-PEAs:VHL-treated mice was decreased about 30\% compared with that in the control group. Due to the limited expression of folate receptors on healthy cells and overexpression in RCC, FAPEAs:pVHL complexes could specifically bind to the cell surface via a ligand-receptor incorporating mechanism (Sudimack and Lee, 2000). Thus, the FA-PEAs:VHL complexes could be released into the cytosol through endocytosis to exert therapeutic effects.

Currently, sunitinib is the standard first-line drug for RCC; however, patients inevitably develop resistance to this drug, leading to therapy failure and poor prognosis (Joosten et al., 2015; Stone, 2016). Therefore, new therapies are needed to improve treatment outcomes in patients with RCC. The rapid development of nanotechnology has provided emerging techniques for the treatment of drug-resistant RCC. Yang colleagues demonstrated that cuprous oxide NPs can markedly inhibit RCC tumor growth with minimum renal toxicity in vitro and in vivo, thereby reversing sunitinib resistance. The mechanism may involve the downregulation of copper chaperone proteins antioxidant 1 copper chaperone and copper chaperone for superoxide dismutase in RCC cells, influencing copper trafficking to the endoplasmic reticulum and mitochondria and thereby initiating endoplasmic reticulum stress and mitochondrion-mediated apoptosis by activating caspase-3, caspase-9, and caspase-12 (Yang et al., 2017). In addition, cell cycle and apoptosis regulator 1 functional mimetic compounds (CFMs) inhibit cell growth by inducing apoptosis in various cancer types, even drug-resistant cancer (Muthu et al., 2015). Cheriyan et al. (2017) found that CFM-4.16 had strong inhibitory effects on parental and everolimus-resistant RCC cells. Because of the poor aqueous solubility of CFM-4.16, it was encapsulated in PEGylated vitamin E-based nanomicelles generating water-soluble formulations with higher drug loading $(30 \% \mathrm{w} / \mathrm{w})$. The findings of this study suggested that CFM-4.16 nanomicelles inhibited the viability of parental and everolimusresistant RCC cells in vitro and suppressed the growth of RCC cell-derived xenografts (Cheriyan et al., 2017).

The use of PEG-conjugated antibodies attached to nanoshells guarantees biocompatibility for drug delivery to tumor cells. Pannerec-Varna et al. (2013) developed large PEGylated gold nanoshells with distribution in the different cellular components of human renal cancer. The distribution kinetics progressed from intravascular flow at $30 \mathrm{~min}$ to intratumoral cells $24 \mathrm{~h}$ later, and no toxicity was detected in mice with PEGylated gold nanoshells at 6 months. This novel research provided important insights into the use of large PEGylated gold nanoshells by optimizing the time of targeted hyperthermia or topical drug delivery to carcinoma cells (Pannerec-Varna et al., 2013). Additionally, new studies have shown that diverse tumor types can be evaluated preclinically and clinically using CRLX101, an NP-drug conjugate containing camptothecin conjugated to a biocompatible cyclodextrin/PEG copolymer (Gaur et al., 2014; Lin C.J. et al., 2016). CRLX101 in combination with bevacizumab has been assessed in a phase I trial of mRCC treatment (NCT01625936 ${ }^{1}$ ), and the initial data indicated that

\footnotetext{
${ }^{1}$ https://clinicaltrials.gov/
} 
CRLX101 combined with bevacizumab was an adequate therapy in mRCC. The strategy of using biodegradable polymer NPs to control the delivery of medicines for multiple types of cancers has become feasible, although the therapeutic effects of these biodegradable polymer NPs in RCC are unknown (Schroeder et al., 2012; Devulapally and Paulmurugan, 2014). Nevertheless, Abraxane (albumin NPs conjugated to paclitaxel) was welltolerated for the treatment of metastatic urothelial carcinoma and showed tumor responses in $27.7 \%$ of patients, revealing that this strategy may be a valid second-line treatment (Ko et al., 2013).

Gold NPs can be used in cancer treatment due to their remarkable compatibility, tunable stability, and low toxicity. Moreover, GNPs are often used in photodynamic therapy (PDT) by generating heat to kill tumor cells (Cabuzu et al., 2015). Nikzad et al. (2017) assessed the effects of treatment of RCC with RF radiation in the presence of GNPs. Human embryonic kidney cells were subjected to various tests in the presence of RF and GNPs. In vitro MTT assays showed that cell viability was dramatically reduced in the RF-treated groups in the presence of GNPs compared with that in the control group. Thus, this method may be suitable for the treatment of RCC, providing a new method for alternative nephrectomy (Nikzad et al., 2017).
Sreekanth et al. (2016) used sulforhodamine B assays and twocolor flow cytometry analysis to test the toxic effects of $\mathrm{CdO}$ nanostructures on Madin-Darby canine kidney epithelial cells (MDCK cells) and Caki-2 human renal cancer cells. Compared with normal cells, $\mathrm{CdO}$ had significant cytotoxic effects on MDCK and Caki-2 cells. Thus, CdO could inhibit the growth of tumor cells and may be an effective drug for the treatment of RCC (Sreekanth et al., 2016).

Burke et al. (2009) confirmed the heating effects of treatment with multiwalled carbon nanotubes (MWCNTs) through magnetic resonance temperature-mapping and heat shock protein-reactive immunohistochemistry. The results showed that the use of MWCNTs could ablate tumors with low laser power and reduce treatment times, with minimal local toxicity and no significant systemic toxicity (Figure 2). MWCNTs are thermal ablation agents that can lead to long-term survival in tumor-bearing mice, which indicates that the combination of MWCNTs and laser may be a promising method for the treatment of RCC (Burke et al., 2009).

Recently, because of the low frequency of mechanical effects on cancer cell membranes, some original approaches have been developed to eradicate cancer cells. A study on human renal cancer cells with superparamagnetic-like particles was conducted by Leulmi et al. (2015), who confirmed that apoptosis could be

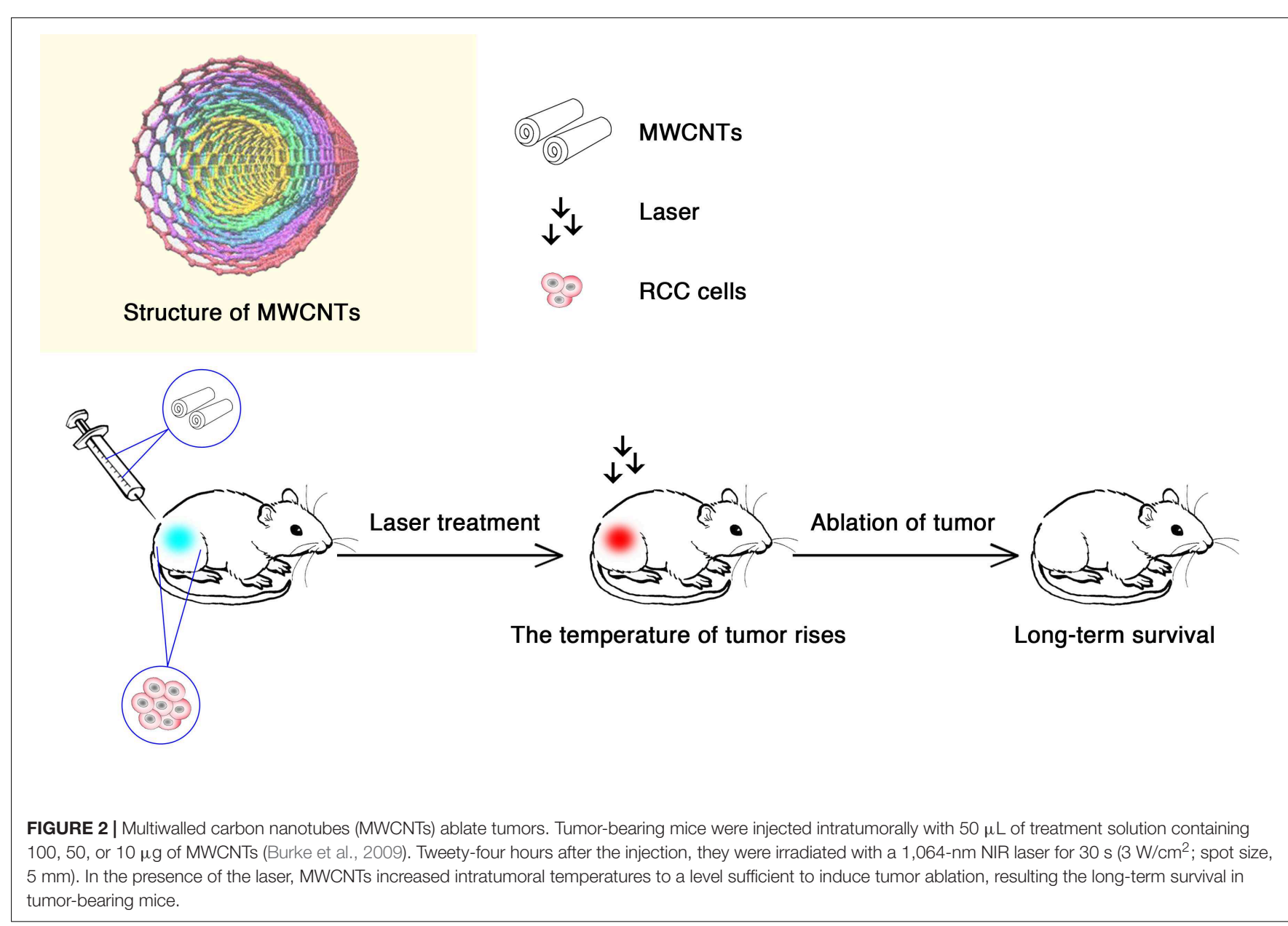


achieved by the vibration of MNPs attached to cancer cells. With regard to the invasiveness of the treatment, magneto-mechanical stimulation is superior to magnetic hyperthermia and is easy to put into practice (Drexler, 1986).

\section{NANOTECHNOLOGY IN BLADDER CANCER}

Bladder cancer is the seventh most commonly diagnosed cancer in the male population worldwide (Babjuk et al., 2017), and can be divided into non-muscle-invasive bladder cancer (NMIBC) and muscle-invasive bladder cancer (MIBC) according to the pathologic stage (Jiang et al., 2015). At diagnosis, approximately $75 \%$ of patients with BCa present with NMIBC (Babjuk et al., 2017). The most common method for detection of NMIBC is standard white light cystoscopy; however, it is difficult to detect flat lesions and differentiate benign from malignant lesions. TUR-BT, as the gold standard for primary treatment for NMIBC, frequently leads to tumor relapse. To prevent recurrence, various medicines, including BCG and mitomycin $\mathrm{C}$, have been used extensively through intravesical instillation as adjuvant therapy after TUR-BT. However, these treatments can cause septicemia, disseminated intravascular coagulation, and multiple organ failure because of severe toxicity (Lodde et al., 2014). Therefore, more advanced diagnosis and therapies are needed (Table 1).

\section{Imaging in Bladder Cancer}

For the detection of NMIBC, fluorescent or photodynamic diagnosis has been developed as an improvement for contemporary white light microscopy. Photosensitizers, such as hexaminolevulinate, are used in fluorescence cystoscopy and are preferentially absorbed by cancer cells, resulting in a red appearance in comparison with surrounding tissues. Although these compounds exhibit high sensitivity, they may show low specificity, particularly after BCG therapy (Ray et al., 2010). Previous studies have shown that nanotechnology can enhance the specificity of photosensitizers to tumor cells and improve the identification of cancer by increasing the uptake of NPs within tumor cells (Olivo et al., 2012; Yan et al., 2013). Recently, Lin T.Y. et al. (2016) developed a multifunctional nanoporphyrin called PLZ4-nanoporphyrin (PNP) due to its coating with the BCaspecific ligand PLZ4. PNP displays the ability to preferably emit fluorescence/heat/reactive oxygen species upon illumination with near infrared light, allowing the fluorescence signal of PNPs to efficiently and selectively increase in BCa cells.

As metal NPs, GNPs can be modified with functional groups by being combined with ligands, antibodies, and other medicines (Cheng et al., 2014). Due to its characteristic SPR signal according to the distance of NPs, GNPs can modify protein molecules and particular nucleic acids to show different colors (Larguinho and Baptista, 2012). Because of SPR, colloidal GNPs are red in color and can be 4-5 orders of magnitude larger than the traditional dye in absorption and scattering cross-sections (Azzazy et al., 2006). These properties can be used to develop easier and faster methods for diagnosing diseases. When GNPs aggregate, their color changes from red to blue due to a second phenomenon known as plasmon-plasmon transfer (Huang and El-Sayed, 2010). The rationale is that GNPs are stabilized by the adsorption of single-stranded DNA through their nitrogenous bases, preventing the salt-induced aggregation of GNPs and keeping the solution red in color. In contrast, the repulsion between the GNP surface and double-stranded DNA (dsDNA) prevents dsDNA from adsorbing to the NP surface (Li and Rothberg, 2004, 2005); because of this, GNPs are not protected from salt-induced aggregation, and the color of the solution turns blue.

Based on these phenomena, Eissa et al. (2014) have developed colorimetric GNP assays to detect unamplified hepatoma upregulated protein RNA (HURP RNA) in urine directly for $\mathrm{BCa}$ diagnosis. The principle is shown in Figure 3A. Briefly, the purified HURP RNA was mixed with hybridization buffer containing $\mathrm{NaCl}$ and a specific oligotargeter. After denaturation and annealing, hybridization between the oligotargeter and the HURP RNA occurred, and the added GNPs were aggregated without the protection of the oligotargeter. The solution color then shifted from red to blue. If there was no HURP RNA in the samples, the GNP surface was fully adsorbed with the oligotargeter, and the solution color remained red. Using this sensitive and non-invasive assay, BCa could be detected at an early stage, making it possible to begin treatment earlier and achieve better therapeutic effects. In another study, GNPs were also developed for rapid and sensitive detection of urinary hyaluronidase (HAase) activity (Nossier et al., 2014). The charge interaction between polyanionic hyaluronic acid (HA) and cationic GNPs stabilized with cetyl trimethyl ammonium bromide can lead to the formation of gold aggregates and a red to blue color shift. After the enzymatic reaction of HAase, the polymeric HA is degraded into small fragments that cannot aggregate GNPs (Figure 3B). Similarly, the developed cationic GNP assay was used for qualitative detection of urinary HAase activity (a urinary marker of $\mathrm{BCa}$ ) in patients with bladder carcinoma by detecting the absorption ratio $\left(A_{530} / A_{620}\right)$ of the reacted GNP solution, which showed a better sensitivity $(82.5 \%)$ than that of zymography (Nossier et al., 2014).

Nuclear matrix protein 22 (NMP22) is a monitoring tool for predicting the recurrence/clearance of $\mathrm{BCa}$ and for screening undiagnosed individuals who have symptoms or are at risk for the disease. Lee colleagues demonstrated a novel strategy to sense NMP22 in urine samples by using a sensing element comprised of molecularly imprinted polymers (MIPs) to specifically recognize NMP22 molecules. In this study, zinc oxide nanorods were hydrothermally grown on the sensing electrodes to increase the surface area to be coated with MIPs and therefore enhance the electrochemical response (Lee et al., 2016).

\section{Therapeutics in Bladder Cancer}

Liposomes as carriers of molecules, such as small-molecule cytotoxic agents (Guhasarkar et al., 2017), nucleotides (Cuomo et al., 2013), and proteins (Vila-Caballer et al., 2016), have also been developed for BCa therapy. To improve the poor solubility and enhance the efficiency of the cell wall skeleton (CWS) of BCG, Nakamura's group encapsulated the CWS of BCG within 


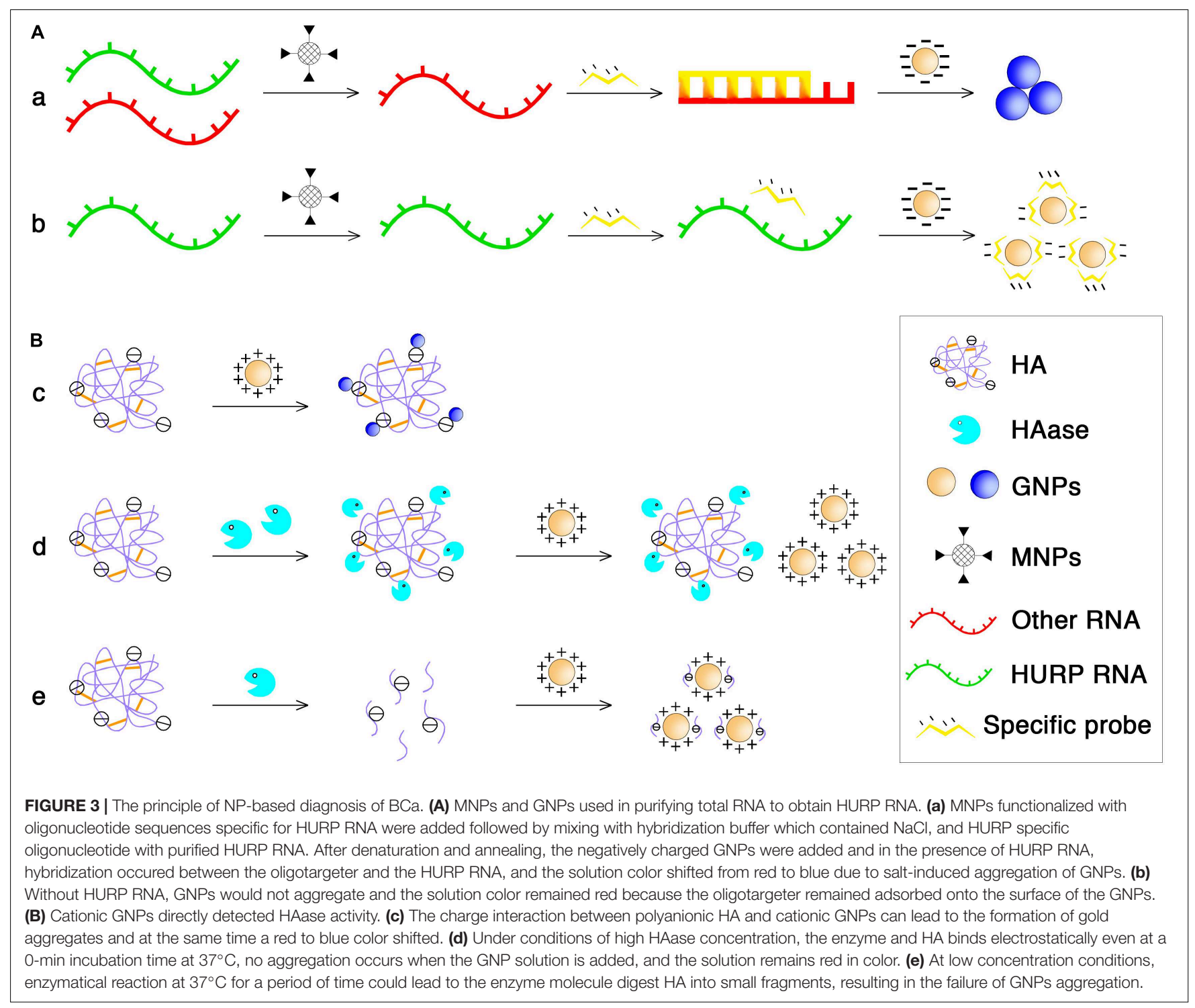

liposomes (Nakamura et al., 2014). Recently, they modified cationic liposomal surfaces with cholesteryl-PEG to overcome urine aggregation and promote cellular uptake into cancerous urothelial tissues (Nakamura et al., 2017). Liposomes can be also used to envelop small interfering RNA (siRNA) silencing oncogenes or other tumor-related genes for the prevention or treatment of BCa. Cui et al. (2015) adopted two newly developed PEGylated cationic liposome carriers (PCat, PPCat) for delivering survivin siRNA (siSurvivin) and enhancing the activity of mitomycin C in human BCa cells. A fusogenic lipid was used in both carriers to destabilize the endosomal membrane, and PPCat further contained paclitaxel to enhance the in vivo delivery and transfection of siSurvivin.

Several studies have shown that polymeric NPs as drug carriers have great promise in the treatment of $\mathrm{BCa}$ (Huang et al., 2012; Yan et al., 2013). To utilize polymeric NPs as carriers, the polymers must have a biodegradable structure and show changes in composition to carry a specific drug to a specified location to achieve targeted drug delivery. The improved polymeric NPs also need to be less expensive, easier to synthesize, and non-immunogenic. One of the most widely used polymeric NPs is PLGA NPs, which show outstanding biocompatibility, biodegradability, ability to be modified with polymers and peptides (Cu et al., 2011), and ability to facilitate controlled release of loaded drugs (Hua et al., 2014). Martin et al. (2013) designed PLGA NPs loaded with belinostat, a histone deacetylase inhibitor, for $\mathrm{BCa}$ treatment. PLGA NPs were surface modified with a novel cell penetrating polymer, poly(guanidinium oxanorbornene). The results showed that intracellular uptake was also enhanced significantly and tissue penetration ability was improved by 10 -fold in intravesically treated mouse bladders and ex vivo human ureters. In a subsequent study, researchers used a low-molecular-weight (2.5 or $20 \mathrm{kDa})$ positively charged mucoadhesive polysaccharide, chitosan, to modify the surface of PLGA NPs in order to deliver siSurvivin to 
the BCa cells (Martin et al., 2014). These surface-modified PLGA NPs could not only cross the urothelium and target the exact tumor site but also load a large number of siRNAs.

Protein NPs have been used as drug carriers in the treatment of many cancers (Lee et al., 2017; Palchetti et al., 2017). Using proteins as carrier materials in vivo may solve enzymeinduced degradation problems, reduce the effects of drug toxicity, and offer good biocompatibility compared with other types of materials, such as metals. The production of urine during treatment leads to dilution of the drug concentration used for intravesical instillation, resulting in the failure of intravesical treatment of NMIBC. However, studies have found that the use of paclitaxel-gelatin NPs can solve the problem of drug dilution by newly produced urine through constant drug release and that achieving a constant drug concentration can reduce the frequency of treatment. For example, paclitaxel-loaded gelatin protein NPs have been developed to improve the delivery and retention properties of paclitaxel in intravesical therapy against BCa (Lu et al., 2011). Compared with docetaxel, NP albumin-bound paclitaxel (Nab-paclitaxel) has been shown to have increased solubility and lower toxicity in systemic treatment, and minimal toxicity and systemic absorption were demonstrated in the first human intravesical phase I trial (McKiernan et al., 2011). Phase II trials have shown that Nab-paclitaxel is welltolerated in patients with pretreated advanced urothelial cancer and has a good tumor response (Ko et al., 2013). These results have highlighted the potential applications of Nab-paclitaxel in cancer treatment.

Recently, novel MNPs coated with three broad-spectrum lectins, namely concanavalin A (ConA; MNP@ConA), wheat germ agglutinin (WGA; MNP@WGA), and Sambucus nigra (SNA; MNP@SNA), have been developed to selectively capture glycoproteins from the urine of patients with different types of BCa (Azevedo et al., 2018). In this case, lectins were used for targeting glycan moieties in cancer-associated glycoproteins, indicating the possibility of targeting local release of drugs.

The optical properties of SPR are used to assist laser-induced thermotherapy in plasmonic photothermal therapy (PTT) with GNPs to enhance the effects of target therapy (Nergiz et al., 2014), avoiding damage to neighboring normal tissues because of the hyperthermic state induced by the relatively low laser power. Chen et al. (2015b) showed that GNPs require only half the laser power of regular laser treatment, and Cheng et al. (2009) demonstrated that silica-Au nanoshells, Au/Ag nanospheres, and $\mathrm{Au}$ nanorods modified with tumor targeting antibodies, such as anti-epidermal growth factor receptor and anti-epidermal growth factor receptor 2 antibodies, were internalized by tumor cells, resulting in photothermal-induced death of BCa cells in vitro. Among the three types of nanomaterials, silica@Au nanoshells require a minimum number of particles to produce effective photodestruction. In contrast, PDT is also a promising strategy for BCa therapy, involving the use of photosensitizers, which are usually large cyclic compounds, such as porphyrins, chlorins, and phthalocyanines. These substances will produce free radicals when exposed to near infrared or visible light. However, the products currently on the market have quite a few limitations, including specific differences in the ability to act on the tumor alone (Juarranz et al., 2008). In a recent study, Long et al. (2018) designed a novel multifunctional nanoporphyrin platform loaded with the heat-shock protein 90 inhibitor 17AAG (NP-AAG) and found that bladder tumors could be synergistically eradicated with a single intravenous injection of NP-AAG followed by multiple light treatments within 7 days.

\section{NANOTECHNOLOGY IN OTHER UROLOGICAL CANCER}

Other urological carcinomas have received limited attention with regard to nanotechnology applications. Feldman et al. (2008) conducted a preliminary study of the potential of USPIOs for accurate detection of lymph node metastases of penile and testicular cancers through lymphotropic NPenhanced MRI. Patients with penile carcinoma underwent a pelvic MRI after using USPIOs. The results showed that better sensitivity, specificity, and accuracy could be obtained by comparing conventional imaging techniques, suggesting that the pathological status of local lymph nodes could be accurately predicted by MRI in patients with penile cancer (Tabatabaei et al., 2005; Mueller-Lisse et al., 2008; Hughes et al., 2009). Similarly, a prospective pilot study examined the use of lymphotropic NPenhanced MRI to detect lymph node metastasis in patients with testicular cancer after injection of USPIOs. The data suggested that USPIOs greatly improved the specificity and sensitivity of accurate lymph node metastasis diagnosis (Harisinghani et al., 2005).

\section{FUTURE PERSPECTIVES}

Despite the use of nanotechnologies with tremendous potential for the detection, diagnosis, and treatment of urological cancers, more studies are still required. First, safety profiles must be studied in detail because of insufficient knowledge regarding the biocompatibility of nanocarriers. The safety of GNPs and gold nanoshells has been widely evaluated in preclinical trials, and full clinical trials are still underway for many of these materials. USPIOs have been under continued scrutiny, and ferumoxtran-10 is currently entering phase III clinical trials in Europe (Daldrup-Link, 2017). Additionally, iron-oxide NPs have been approved as an MRI contrast agent by the US Food and Drug Administration (Wang et al., 2014). A database on health risks linked to different types of NPs should also be established according to different pharmacokinetic behaviors. Second, additional research into the design and development of NPs with multiple functions (single or dual imaging, targeted therapy, and combination therapy) is needed. Moreover, the development of multifunctional NPs loaded with targeted agents may eventually be permitted for both PTT and targeted therapy to achieve simultaneous detection and treatment of urological cancer. Third, a widely used and well-accepted dosimetry model is needed to estimate the NP concentration in tumors of interest. Dosimetry formulations have been used to guide radiation 
therapy, but not for PTT because of the uneven distribution of particles and the effects of tissue physiology. Thus, further studies are required to establish such formulas. Lastly, in the future, more studies are needed to examine the environmental influence of manufactured NPs, which are deliberately produced with specific properties; these NPs have been shown to enter air, water, and soil from a range of routes (Kumar et al., 2012). Thus, there is an urgent need for the development of safety guidelines for NPs.

\section{CONCLUSION}

During recent decades, many efforts have been made to combine novel technologies and conventional methods to combat cancer. The potential applications of nanotechnology were reviewed in this article. Nanotechnologies are promising tools to enhance the specificity and sensitivity of both the diagnosis and treatment of cancer and have been shown to have several feasible applications in urological cancer. Many studies and clinical trials have demonstrated that NPs can overcome the limitations of current medical approaches. Various metallic nanomaterials are used as contrast agents for MRI and CT imaging, providing a higher probability of detecting early urological cancer. The excellent photothermal properties of GNPs have led to their extensive application in imaging. Moreover, by application in HT therapy and thermal therapy, GNPs have shown potential to generate heat more efficiently. In contrast, many researchers have clearly demonstrated that NPs are ideal candidates for drug delivery systems because of their special size and are able to combine

\section{REFERENCES}

Agarwal, A., Huang, S. W., Odonnell, M., and Day, K. C. (2007). Targeted gold nanorod contrast agent for prostate cancer detection by photoacoustic imaging. J. Appl. Phys. 102:064701. doi: 10.1063/1.2777127

Arnida, Malugin, A., and Ghandehari, H. (2010). Cellular uptake and toxicity of gold nanoparticles in prostate cancer cells: a comparative study of rods and spheres. J. Appl. Toxicol. 30, 212-217. doi: 10.1002/jat.1486

Attaluri, A., Kandala, S. K., Wabler, M., Zhou, H., Cornejo, C., Armour, M., et al. (2015). Magnetic nanoparticle hyperthermia enhances radiation therapy: a study in mouse models of human prostate cancer. Int. J. Hyperthermia 31, 359-374. doi: 10.3109/02656736.2015.1005178

Azevedo, R., Soares, J., Gaiteiro, C., Peixoto, A., Lima, L., Ferreira, D., et al. (2018). Glycan affinity magnetic nanoplatforms for urinary glycobiomarkers discovery in bladder cancer. Talanta 184, 347-355. doi: 10.1016/j.talanta.2018.03.028

Azzazy, H. M., Mansour, M. M., and Kazmierczak, S. C. (2006). Nanodiagnostics: a new frontier for clinical laboratory medicine. Clin. Chem. 52, 1238-1246. doi: 10.1373/clinchem.2006.066654

Babjuk, M., Bohle, A., Burger, M., Capoun, O., Cohen, D., Comperat, E. M., et al. (2017). EAU guidelines on non-muscle-invasive urothelial carcinoma of the bladder: update 2016. Eur. Urol. 71, 447-461. doi: 10.1016/j.eururo.2016.05.041

Bertrand, N., Wu, J., Xu, X., Kamaly, N., and Farokhzad, O. C. (2014). Cancer nanotechnology: the impact of passive and active targeting in the era of modern cancer biology. Adv. Drug Deliv. Rev. 66, 2-25. doi: 10.1016/j.addr.2013.11.009

Bhattacharya, C., Yu, Z., Rishel, M. J., and Hecht, S. M. (2014). The carbamoylmannose moiety of bleomycin mediates selective tumor cell targeting. Biochemistry 53, 3264-3266. doi: 10.1021/bi500482q

Bouchelouche, K. (2016). "Diagnostic applications of nuclear medicine: kidney and bladder cancer," in Nuclear Oncology: From Pathophysiology to Clinical Applications, eds H. W. Strauss, G. Mariani, D. Volterrani, and S. M. Larson (Cham: Springer International Publishing), 1-43. the benefits of drug delivery systems with improved safety and efficacy. Polymeric NPs have the capacity to be used for various applications from imaging to drug delivery systems. Several different types of polymeric materials can be used, and well-developed fabrication techniques have enabled them to be mass produced. Multifunctional NPs have many advantages because they are uniquely designed to target specific cancer cells. However, there are still some issues that need to be clarified, such as the safety of these NPs when used in the human body. Additional studies are still needed to clarify the details of nanotechnology-based methods and to establish these NPs as tools for the treatment of cancers.

\section{AUTHOR CONTRIBUTIONS}

M-HH, LC, TZ, and YT summarized the literatures and wrote the manuscript. QH and H-LF revised and edited the manuscript. J-CL, WZ, and GS provided critical comments and revised the manuscript. LH and Z-XY revised the manuscript and supervised all the works.

\section{FUNDING}

This work was supported by the project (2016M602706) funded by China Postdoctoral Science Foundation and the International Exchange and Collaboration Project (2018HH0057) funded by Science and Technology Department of Sichuan Province.

Brazhnik, K., Sokolova, Z., Baryshnikova, M., Bilan, R., Efimov, A., Nabiev, I., et al. (2015). Quantum dot-based lab-on-a-bead system for multiplexed detection of free and total prostate-specific antigens in clinical human serum samples. Nanomedicine 11, 1065-1075. doi: 10.1016/j.nano.2015.03.003

Burke, A., Ding, X., Singh, R., Kraft, R. A., Levi-Polyachenko, N., Rylander, M. N., et al. (2009). Long-term survival following a single treatment of kidney tumors with multiwalled carbon nanotubes and near-infrared radiation. Proc. Natl. Acad. Sci. U.S.A. 106, 12897-12902. doi: 10.1073/pnas.0905195106

Cabuzu, D., Cirja, A., Puiu, R., and Grumezescu, A. M. (2015). Biomedical applications of gold nanoparticles. Curr. Top. Med. Chem. 15, 1605-1613. doi: 10.2174/1568026615666150414144750

Chen, C. H., Chan, T. M., Wu, Y. J., and Chen, J. J. (2015a). Review: application of nanoparticles in urothelial cancer of the urinary bladder. J. Med. Biol. Eng. 35, 419-427.

Chen, C. H., Wu, Y. J., and Chen, J. J. (2015b). Gold nanotheranostics: photothermal therapy and imaging of Mucin 7 conjugated antibody nanoparticles for urothelial cancer. Biomed Res. Int. 2015:813632. doi: 10.1155/ 2015/813632

Cheng, D., Han, W., Yang, K., Song, Y., Jiang, M., and Song, E. (2014). One-step facile synthesis of hyaluronic acid functionalized fluorescent gold nanoprobes sensitive to hyaluronidase in urine specimen from bladder cancer patients. Talanta 130, 408-414. doi: 10.1016/j.talanta.2014.07.005

Cheng, F. Y., Chen, C. T., and Yeh, C. S. (2009). Comparative efficiencies of photothermal destruction of malignant cells using antibody-coated silica@Au nanoshells, hollow $\mathrm{Au} / \mathrm{Ag}$ nanospheres and $\mathrm{Au}$ nanorods. Nanotechnology 20:425104. doi: 10.1088/0957-4484/20/42/425104

Cheng, Z., Al Zaki, A., Hui, J. Z., Muzykantov, V. R., and Tsourkas, A. (2012). Multifunctional nanoparticles: cost versus benefit of adding targeting and imaging capabilities. Science 338, 903-910. doi: 10.1126/science.1226338

Cheriyan, V. T., Alsaab, H. O., Sekhar, S., Stieber, C., Kesharwani, P., Sau, S., et al. (2017). A CARP-1 functional mimetic loaded vitamin E-TPGS micellar 
nano-formulation for inhibition of renal cell carcinoma. Oncotarget 8, 104928 104945. doi: 10.18632/oncotarget.20650

Crouzet, S., Rouviere, O., Martin, X., and Gelet, A. (2014). High-intensity focused ultrasound as focal therapy of prostate cancer. Curr. Opin. Urol. 24, 225-230. doi: 10.1097/MOU.0000000000000053

Cu, Y., Booth, C. J., and Saltzman, W. M. (2011). In vivo distribution of surfacemodified PLGA nanoparticles following intravaginal delivery. J. Control. Release 156, 258-264. doi: 10.1016/j.jconrel.2011.06.036

Cui, M. J., Au, J. L. S., Wientjes, M. G., O’Donnell, M. A., Loughlin, K. R., and $\mathrm{Lu}, \mathrm{Z}$. (2015). Intravenous siRNA silencing of survivin enhances activity of mitomycin C in human bladder RT4 xenografts. J. Urol. 194, 230-237. doi: 10.1016/j.juro.2015.02.036

Cuomo, F., Mosca, M., Murgia, S., Avino, P., Ceglie, A., and Lopez, F. (2013). Evidence for the role of hydrophobic forces on the interactions of nucleotidemonophosphates with cationic liposomes. J. Colloid Interface Sci. 410, 146-151. doi: $10.1016 /$ j.jcis.2013.08.013

Daldrup-Link, H. E. (2017). Ten things you might not know about iron oxide nanoparticles. Radiology 284, 616-629. doi: 10.1148/radiol.2017162759

Daniel, M. C., and Astruc, D. (2004). Gold nanoparticles: assembly, supramolecular chemistry, quantum-size-related properties, and applications toward biology, catalysis, and nanotechnology. Chem. Rev. 104, 293-346. doi: 10.1021/ cr030698+

Datta, N. R., Ordonez, S. G., Gaipl, U. S., Paulides, M. M., Crezee, H., Gellermann, J., et al. (2015). Local hyperthermia combined with radiotherapy and-/or chemotherapy: recent advances and promises for the future. Cancer Treat. Rev. 41, 742-753. doi: 10.1016/j.ctrv.2015.05.009

Devulapally, R., and Paulmurugan, R. (2014). Polymer nanoparticles for drug and small silencing RNA delivery to treat cancers of different phenotypes. Wiley Interdiscip Rev Nanomed Nanobiotechnol 6, 40-60. doi: 10.1002/wnan.1242

Djavan, B., and Nasu, Y. (2001). Prostate cancer gene therapy-what have we learned and where are we going? Rev. Urol. 3, 179-186.

Drexler, K. E. (1986). Engines of Creation. New York, NY: Anchor Press.

Eissa, S., Shawky, S. M., Matboli, M., Mohamed, S., and Azzazy, H. M. (2014). Direct detection of unamplified hepatoma upregulated protein RNA in urine using gold nanoparticles for bladder cancer diagnosis. Clin. Biochem. 47, 104-110. doi: 10.1016/j.clinbiochem.2013.10.022

Ekin, A., Karatas, O. F., Culha, M., and Ozen, M. (2014). Designing a gold nanoparticle-based nanocarrier for microRNA transfection into the prostate and breast cancer cells. J. Gene Med. 16, 331-335. doi: 10.1002/jgm.2810

Farber, N. J., Wu, Y., Zou, L., Belani, P., and Singer, E. A. (2015). Challenges in RCC imaging: renal insufficiency, post-operative surveillance, and the role of radiomics. Kidney Cancer J. 13, 84-90.

Feldman, A. S., McDougal, W. S., and Harisinghani, M. G. (2008). The potential of nanoparticle-enhanced imaging. Urol. Oncol. 26, 65-73. doi: 10.1016/j.urolonc. 2007.03.016

Gaur, S., Wang, Y. F., Kretzner, L., Chen, L. L., Yen, T., Wu, X. W., et al. (2014). Pharmacodynamic and pharmacogenomic study of the nanoparticle conjugate of camptothecin CRLX101 for the treatment of cancer. Nanomedicine 10, 1477-1486. doi: 10.1016/j.nano.2014.04.003

Ghasemian, Z., Shahbazi-Gahrouei, D., and Manouchehri, S. (2015). Cobalt zinc ferrite nanoparticles as a potential magnetic resonance imaging agent: an in vitro study. Avicenna J. Med. Biotechnol. 7, 64-68.

Guhasarkar, S., More, P., and Banerjee, R. (2017). Urothelium-adherent, ion-triggered liposome-in-gel system as a platform for intravesical drug delivery. J. Control. Release 245, 147-156. doi: 10.1016/j.jconrel.2016. 11.031

Harisinghani, M. G., Saksena, M., Ross, R. W., Tabatabaei, S., Dahl, D., Mcdougal, S., et al. (2005). A pilot study of lymphotrophic nanoparticleenhanced magnetic resonance imaging technique in early stage testicular cancer: a new method for noninvasive lymph node evaluation. Urology 66, 1066-1071. doi: 10.1016/j.urology.2005.05.049

Hua, X., Tan, S., Bandara, H. M., Fu, Y., Liu, S., and Smyth, H. D. (2014). Externally controlled triggered-release of drug from PLGA micro and nanoparticles. PLoS One 9:e114271. doi: 10.1371/journal.pone.0114271

Huang, C., Neoh, K. G., Xu, L., Kang, E. T., and Chiong, E. (2012). Polymeric nanoparticles with encapsulated superparamagnetic iron oxide and conjugated cisplatin for potential bladder cancer therapy. Biomacromolecules 13, 2513-2520. doi: 10.1021/bm300739w
Huang, H. C., Chang, P. Y., Chang, K., Chen, C. Y., Lin, C. W., Chen, J. H., et al. (2009). Formulation of novel lipid-coated magnetic nanoparticles as the probe for in vivo imaging. J. Biomed. Sci. 16:86. doi: 10.1186/1423-0127-16-86

Huang, X., and El-Sayed, M. A. (2010). Gold nanoparticles: optical properties and implementations in cancer diagnosis and photothermal therapy. J. Adv. Res. 1, 13-28. doi: 10.1016/j.jare.2010.02.002

Hughes, B., Leijte, J., Shabbir, M., Watkin, N., and Horenblas, S. (2009). Noninvasive and minimally invasive staging of regional lymph nodes in penile cancer. World J. Urol. 27, 197-203. doi: 10.1007/s00345-008-0288-6

Hurwitz, M. D., Hansen, J. L., Prokopios-Davos, S., Manola, J., Wang, Q., Bornstein, B. A., et al. (2011). Hyperthermia combined with radiation for the treatment of locally advanced prostate cancer: long-term results from DanaFarber Cancer Institute study 94-153. Cancer 117, 510-516. doi: 10.1002/cncr. 25619

Jeong, N. Y., Yoon, Y. G., Rho, J. H., Lee, J. S., Lee, S. Y., Yoo, K. S., et al. (2011). The novel resveratrol analog HS-1793-induced polyploid LNCaP prostate cancer cells are vulnerable to downregulation of Bcl-xL. Int. J. Oncol. 38, 1597-1604. doi: 10.3892/ijo.2011.979

Jiang, X., Du, L., Wang, L., Li, J., Liu, Y., Zheng, G., et al. (2015). Serum microRNA expression signatures identified from genome-wide microRNA profiling serve as novel noninvasive biomarkers for diagnosis and recurrence of bladder cancer. Int. J. Cancer 136, 854-862. doi: 10.1002/ijc.29041

Johannsen, M., Gneueckow, U., Thiesen, B., Taymoorian, K., Cho, C. H., Waldofner, N., et al. (2007a). Thermotherapy of prostate cancer using magnetic nanoparticles: feasibility, imaging, and three-dimensional temperature distribution. Eur. Urol. 52, 1653-1662. doi: 10.1016/j.eururo.2006.11.023

Johannsen, M., Gneveckow, U., Eckelt, L., Feussner, A., Waldofner, N., Scholz, R., et al. (2005a). Clinical hyperthermia of prostate cancer using magnetic nanoparticles: presentation of a new interstitial technique. Int. J. Hyperthermia 21, 637-647.

Johannsen, M., Gneveckow, U., Taymoorian, K., Thiesen, B., Waldofner, N., Scholz, R., et al. (2007b). Morbidity and quality of life during thermotherapy using magnetic nanoparticles in locally recurrent prostate cancer: results of a prospective phase I trial. Int. J. Hyperthermia 23, 315-323.

Johannsen, M., Thiesen, B., Jordan, A., Taymoorian, K., Gneveckow, U., Waldofner, N., et al. (2005b). Magnetic fluid hyperthermia (MFH)reduces prostate cancer growth in the orthotopic Dunning R3327 rat model. Prostate 64, 283-292.

Johannsen, M., Thiesen, B., Wust, P., and Jordan, A. (2010). Magnetic nanoparticle hyperthermia for prostate cancer. Int. J. Hyperthermia 26, 790-795. doi: $10.3109 / 02656731003745740$

Johnson, J. J., Bailey, H. H., and Mukhtar, H. (2010). Green tea polyphenols for prostate cancer chemoprevention: a translational perspective. Phytomedicine 17, 3-13. doi: 10.1016/j.phymed.2009.09.011

Joosten, S. C., Hamming, L., Soetekouw, P. M., Aarts, M. J., Veeck, J., van Engeland, M., et al. (2015). Resistance to sunitinib in renal cell carcinoma: from molecular mechanisms to predictive markers and future perspectives. Biochim. Biophys. Acta 1855, 1-16. doi: 10.1016/j.bbcan.2014.11.002

Jordan, A., Wust, P., Fahling, H., John, W., Hinz, A., and Felix, R. (1993). Inductive heating of ferrimagnetic particles and magnetic fluids: physical evaluation of their potential for hyperthermia. Int. J. Hyperthermia 9, 51-68. doi: 10.3109/ 02656739309061478

Jorgo, K., Agoston, P., Major, T., Takacsi-Nagy, Z., and Polgar, C. (2017). Transperineal gold marker implantation for image-guided external beam radiotherapy of prostate cancer : a single institution, prospective study. Strahlenther. Onkol. 193, 452-458. doi: 10.1007/s00066-017-1104-2

Juarranz, A., Jaen, P., Sanz-Rodriguez, F., Cuevas, J., and Gonzalez, S. (2008). Photodynamic therapy of cancer. Basic principles and applications. Clin. Transl. Oncol. 10, 148-154. doi: 10.1007/s12094-008-0172-2

Kim, D., Jeong, Y. Y., and Jon, S. (2010). A drug-loaded aptamer-gold nanoparticle bioconjugate for combined $\mathrm{CT}$ imaging and therapy of prostate cancer. ACS Nano 4, 3689-3696. doi: 10.1021/nn901877h

Kliton, J., Agoston, P., Szabo, Z., Major, T., and Polgar, C. (2014). [Use of gold radionuclide markers implanted into the prostate for imageguided radiotherapy in prostate cancer: side effects caused by the marker implantation]. Magy. Onkol. 58, 182-187.

Ko, Y. J., Canil, C. M., Mukherjee, S. D., Winquist, E., Elser, C., Eisen, A., et al. (2013). Nanoparticle albumin-bound paclitaxel for second-line treatment of 
metastatic urothelial carcinoma: a single group, multicentre, phase 2 study. Lancet Oncol. 14, 769-776. doi: 10.1016/S1470-2045(13)70162-1

Kondylis, F. I., Demirci, S., Ladaga, L., Kolm, P., and Schellhammer, P. F. (2000). Outcomes after intravesical bacillus Calmette-Guerin are not affected by substaging of high grade T1 transitional cell carcinoma. J. Urol. 163, 1120-1123. doi: 10.1016/S0022-5347(05)67706-3

Krishnan, S., Diagaradjane, P., and Cho, S. H. (2010). Nanoparticle-mediated thermal therapy: evolving strategies for prostate cancer therapy. Int. J. Hyperthermia 26, 775-789. doi: 10.3109/02656736.2010.485593

Kulkarni, A. A., Vijaykumar, V. E., Natarajan, S. K., Sengupta, S., and Sabbisetti, V.S. (2016). Sustained inhibition of cMET-VEGFR2 signaling using liposomemediated delivery increases efficacy and reduces toxicity in kidney cancer. Nanomedicine 12, 1853-1861. doi: 10.1016/j.nano.2016.04.002

Kumar, N. B., Pow-Sang, J., Egan, K. M., Spiess, P. E., Dickinson, S., Salup, R., et al. (2015). Randomized, placebo-controlled trial of green tea catechins for prostate cancer prevention. Cancer Prev. Re.s 8, 879-887. doi: 10.1158/19406207.CAPR-14-0324

Kumar, P., Kumar, A., and Lead, J. R. (2012). Nanoparticles in the Indian environment: known, unknowns and awareness. Environ. Sci. Technol. 46, 7071-7072. doi: 10.1021/es302308h

Larguinho, M., and Baptista, P. V. (2012). Gold and silver nanoparticles for clinical diagnostics - From genomics to proteomics. J. Proteomics 75, 2811-2823. doi: 10.1016/j.jprot.2011.11.007

Lee, J. J., Kang, J. A., Ryu, Y., Han, S. S., Nam, Y. R., Rho, J. K., et al. (2017). Genetically engineered and self-assembled oncolytic protein nanoparticles for targeted cancer therapy. Biomaterials 120, 22-31. doi: 10.1016/j.biomaterials. 2016.12.014

Lee, M. H., Thomas, J. L., Chang, Y. C., Tsai, Y. S., Liu, B. D., and Lin, H. Y. (2016). Electrochemical sensing of nuclear matrix protein 22 in urine with molecularly imprinted poly(ethylene-co-vinyl alcohol) coated zinc oxide nanorod arrays for clinical studies of bladder cancer diagnosis. Biosens. Bioelectron. 79, 789-795. doi: 10.1016/j.bios.2016.01.005

Leulmi, S., Chauchet, X., Morcrette, M., Ortiz, G., Joisten, H., Sabon, P., et al. (2015). Triggering the apoptosis of targeted human renal cancer cells by the vibration of anisotropic magnetic particles attached to the cell membrane. Nanoscale 7, 15904-15914. doi: 10.1039/c5nr03518j

Leveillee, R. J., Castle, S. M., Gorbatiy, V., Salas, N., Narayanan, G., Morillo-Burgos, G., et al. (2013). Oncologic outcomes using real-time peripheral thermometry-guided radiofrequency ablation of small renal masses. J. Endourol. 27, 480-489. doi: 10.1089/end.2012.0305

Li, H., and Rothberg, L. (2005). Detection of specific sequences in RNA using differential adsorption of single-stranded oligonucleotides on gold nanoparticles. Anal. Chem. 77, 6229-6233. doi: 10.1021/ac050921y

Li, H., and Rothberg, L. J. (2004). Label-free colorimetric detection of specific sequences in genomic DNA amplified by the polymerase chain reaction. J. Am. Chem. Soc. 126, 10958-10961. doi: 10.1021/ja048749n

Lin, C. J., Lin, Y. L., Luh, F., Yen, Y., and Chen, R. M. (2016). Preclinical effects of CRLX101, an investigational camptothecin-containing nanoparticle drug conjugate, on treating glioblastoma multiforme via apoptosis and antiangiogenesis. Oncotarget 7, 42408-42421. doi: 10.18632/oncotarget.9878

Lin, T. Y., Li, Y., Liu, Q., Chen, J. L., Zhang, H., Lac, D., et al. (2016). Novel theranostic nanoporphyrins for photodynamic diagnosis and trimodal therapy for bladder cancer. Biomaterials 104, 339-351. doi: 10.1016/j.biomaterials.2016. 07.026

Liu, D., Huang, X., Wang, Z., Jin, A., Sun, X., Zhu, L., et al. (2013). Gold nanoparticle-based activatable probe for sensing ultralow levels of prostatespecific antigen. ACS Nano 7, 5568-5576. doi: 10.1021/nn401837q

Liu, J., Boonkaew, B., Arora, J., Mandava, S. H., Maddox, M. M., Chava, S., et al. (2015a). Comparison of sorafenib-loaded poly (lactic/glycolic) acid and DPPC liposome nanoparticles in the in vitro treatment of renal cell carcinoma. J. Pharm. Sci. 104, 1187-1196. doi: 10.1002/jps.24318

Liu, J., Boonkaew, B., Mandava, S. H., Arora, J., Maddox, M., Chava, S., et al. (2015b). In vitro performance of sorafenib-loaded plga and liposome nanoparticles as a delivery system in the treatment of renal cell carcinoma. J. Urol. 193, E454-E455. doi: 10.1016/j.juro.2015.02.751

Lodde, M., Mian, C., Mayr, R., Comploj, E., Trenti, E., Melotti, R., et al. (2014). Recurrence and progression in patients with non-muscle invasive bladder cancer: prognostic models including multicolor fluorescence in situ hybridization molecular grading. Int. J. Urol. 21, 968-972. doi: 10.1111/iju. 12509

Long, Q., Lin, T.-Y., Huang, Y., Li, X., Ma, A.-H., Zhang, H., et al. (2018). Image-guided photo-therapeutic nanoporphyrin synergized HSP90 inhibitor in patient-derived xenograft bladder cancer model. Nanomedicine 14, 789-799. doi: 10.1016/j.nano.2017.12.014

Lu, C., Li, J., Xu, K., Yang, C., Wang, J., Han, C., et al. (2014). Fabrication of mAb G250-SPIO molecular magnetic resonance imaging nanoprobe for the specific detection of renal cell carcinoma in vitro. PLoS One 9:e101898. doi: 10.1371/journal.pone.0101898

Lu, L., Li, K., Mao, Y. H., Qu, H., Yao, B., Zhong, W. W., et al. (2017). Gold-chrysophanol nanoparticles suppress human prostate cancer progression through inactivating AKT expression and inducing apoptosis and ROS generation in vitro and in vivo. Int. J. Oncol. 51, 1089-1103. doi: 10.3892/ijo. 2017.4095

Lu, Z., Yeh, T. K., Wang, J., Chen, L., Lyness, G., Xin, Y., et al. (2011). Paclitaxel gelatin nanoparticles for intravesical bladder cancer therapy. J. Urol. 185, 1478-1483. doi: 10.1016/j.juro.2010.11.091

Lusch, A., Graversen, J. A., Liss, M. A., and Landman, J. (2013). Ablative techniques: radiofrequency and cryotherapy, which is the best? Arch. Esp. Urol. 66, 71-78.

Martin, D. T., Hoimes, C. J., Kaimakliotis, H. Z., Cheng, C. J., Zhang, K., Liu, J., et al. (2013). Nanoparticles for urothelium penetration and delivery of the histone deacetylase inhibitor belinostat for treatment of bladder cancer. Nanomedicine 9, 1124-1134. doi: 10.1016/j.nano.2013.05.017

Martin, D. T., Steinbach, J. M., Liu, J., Shimizu, S., Kaimakliotis, H. Z., Wheeler, M. A., et al. (2014). Surface-modified nanoparticles enhance transurothelial penetration and delivery of survivin siRNA in treating bladder cancer. Mol. Cancer Ther. 13, 71-81. doi: 10.1158/1535-7163.MCT-130502

McKiernan, J. M., Barlow, L. J., Laudano, M. A., Mann, M. J., Petrylak, D. P., and Benson, M. C. (2011). A phase I trial of intravesical nanoparticle albuminbound paclitaxel in the treatment of bacillus Calmette-Guerin refractory nonmuscle invasive bladder cancer. J. Urol. 186, 448-451. doi: 10.1016/j.juro. 2011.03.129

Menter, D. G., Patterson, S. L., Logsdon, C. D., Kopetz, S., Sood, A. K., and Hawk, E. T. (2014). Convergence of nanotechnology and cancer prevention: are we there yet? Cancer Prev. Res. 7, 973-992. doi: 10.1158/1940-6207.CAPR-14-0079

Mieszawska, A. J., Mulder, W. J., Fayad, Z. A., and Cormode, D. P. (2013). Multifunctional gold nanoparticles for diagnosis and therapy of disease. Mol. Pharm. 10, 831-847. doi: 10.1021/mp3005885

Mueller-Lisse, U. G., Scher, B., Scherr, M. K., and Seitz, M. (2008). Functional imaging in penile cancer: PET/computed tomography, MRI, and sentinel lymph node biopsy. Curr. Opin. Urol. 18, 105-110. doi: 10.1097/MOU. 0b013e3282f151fd

Muthu, M., Cheriyan, V. T., and Rishi, A. K. (2015). CARP-1/CCAR1: a biphasic regulator of cancer cell growth and apoptosis. Oncotarget 6, 6499-6510. doi: 10.18632/oncotarget.3376

Nakamura, T., Fukiage, M., Higuchi, M., Nakaya, A., Yano, I., Miyazaki, J., et al. (2014). Nanoparticulation of BCG-CWS for application to bladder cancer therapy. J. Control. Release 176, 44-53. doi: 10.1016/j.jconrel.2013. 12.027

Nakamura, T., Noma, Y., Sakurai, Y., and Harashima, H. (2017). Modifying cationic liposomes with cholesteryl-PEG prevents their aggregation in human urine and enhances cellular uptake by bladder cancer cells. Biol. Pharm. Bull. 40, 234-237. doi: 10.1248/bpb.b16-00770

Nergiz, S. Z., Gandra, N., Tadepalli, S., and Singamaneni, S. (2014). Multifunctional hybrid nanopatches of graphene oxide and gold nanostars for ultraefficient photothermal cancer therapy. ACS Appl. Mater. Interfaces 6, 16395-16402. doi: 10.1021/am504795d

Nikzad, S., Mahmoudi, G., Amini, P., Baradaran-Ghahfarokhi, M., VahdatMoaddab, A., Sharafi, S. M., et al. (2017). Effects of radiofrequency radiation in the presence of gold nanoparticles for the treatment of renal cell carcinoma. J. Renal Inj. Prev. 6, 103-108. doi: 10.15171/jrip.2017.20

Nossier, A. I., Eissa, S., Ismail, M. F., Hamdy, M. A., and Azzazy, H. M. (2014). Direct detection of hyaluronidase in urine using cationic gold nanoparticles: a potential diagnostic test for bladder cancer. Biosens. Bioelectron. 54, 7-14. doi: 10.1016/j.bios.2013.10.024 
Oh, M. H., Yu, J. H., Kim, I., and Nam, Y. S. (2015). Genetically programmed clusters of gold nanoparticles for cancer cell-targeted photothermal therapy. ACS Appl. Mater. Interfaces 7, 22578-22586. doi: 10.1021/acsami.5b07029

Ojha, T., Pathak, V., Shi, Y., Hennink, W. E., Moonen, C. T. W., Storm, G., et al. (2017). Pharmacological and physical vessel modulation strategies to improve EPR-mediated drug targeting to tumors. Adv. Drug Deliv. Rev. 119, 44-60. doi: 10.1016/j.addr.2017.07.007

Olivo, M., Fu, C. Y., Raghavan, V., and Lau, W. K. (2012). New frontier in hypericin-mediated diagnosis of cancer with current optical technologies. Ann. Biomed. Eng. 40, 460-473. doi: 10.1007/s10439-011-0462-7

Palchetti, S., Pozzi, D., Capriottic, A. L., La Barbera, G., Chiozzi, R. Z., Digiacomo, L., et al. (2017). Influence of dynamic flow environment on nanoparticle-protein corona: From protein patterns to uptake in cancer cells. Colloid Surface B 153, 263-271. doi: 10.1016/j.colsurfb.2017.02.037

Pannerec-Varna, M., Ratajczak, P., Bousquet, G., Ferreira, I., Leboeuf, C., Boisgard, R., et al. (2013). In vivo uptake and cellular distribution of gold nanoshells in a preclinical model of xenografted human renal cancer. Gold Bull. 46, 257-265. doi: 10.1007/s13404-013-0115-8

Park, S., Anderson, J. K., Matsumoto, E. D., Lotan, Y., Josephs, S., and Cadeddu, J. A. (2006). Radiofrequency ablation of renal tumors: intermediate-term results. J. Endourol. 20, 569-573. doi: 10.1089/end.2006.20.569

Patra, S., Roy, E., Madhuri, R., and Sharma, P. K. (2015). Nano-iniferter based imprinted sensor for ultra trace level detection of prostate-specific antigen in both men and women. Biosens. Bioelectron. 66, 1-10. doi: 10.1016/j.bios.2014. 10.076

Rassweiler, J., Rassweiler, M. C., Kenngott, H., Frede, T., Michel, M. S., Alken, P., et al. (2013). The past, present and future of minimally invasive therapy in urology: a review and speculative outlook. Minim. Invasive Ther. Allied Technol. 22, 200-209. doi: 10.3109/13645706.2013.816323

Ray, E. R., Chatterton, K., Khan, M. S., Chandra, A., Thomas, K., Dasgupta, P., et al. (2010). Hexylaminolaevulinate fluorescence cystoscopy in patients previously treated with intravesical bacille Calmette-Guerin. BJU Int. 105, 789-794. doi: 10.1111/j.1464-410X.2009.08839.x

Salvador-Morales, C., Gao, W., Ghatalia, P., Murshed, F., Aizu, W., Langer, R., et al. (2009). Multifunctional nanoparticles for prostate cancer therapy. Expert Rev. Anticancer Ther. 9, 211-221. doi: 10.1586/14737140.9.2.211

Sanna, V., Pintus, G., Roggio, A. M., Punzoni, S., Posadino, A. M., Arca, A., et al. (2011). Targeted biocompatible nanoparticles for the delivery of (-)epigallocatechin 3-gallate to prostate cancer cells. J. Med. Chem. 54, 1321-1332. doi: $10.1021 / \mathrm{jm} 1013715$

Sanna, V., and Sechi, M. (2012). Nanoparticle therapeutics for prostate cancer treatment. Nanomedicine 8(Suppl. 1), S31-S36. doi: 10.1016/j.nano.2012.05.009

Sanna, V., Siddiqui, I. A., Sechi, M., and Mukhtar, H. (2013). Nanoformulation of natural products for prevention and therapy of prostate cancer. Cancer Lett. 334, 142-151. doi: 10.1016/j.canlet.2012.11.037

Schroeder, A., Heller, D. A., Winslow, M. M., Dahlman, J. E., Pratt, G. W., Langer, R., et al. (2012). Treating metastatic cancer with nanotechnology. Nat. Rev. Cancer 12, 39-50. doi: 10.1038/nrc3180

Siegel, R. L., Miller, K. D., and Jemal, A. (2018). Cancer statistics, 2018. CA Cancer J. Clin. 68, 7-30. doi: 10.3322/caac. 21442

Skubitz, K. M. (2002). Phase II trial of pegylated-liposomal doxorubicin (Doxil) in renal cell cancer. Invest. New Drugs 20, 101-104. doi: 10.1023/A:1014428720551

Sreekanth, T. V., Pandurangan, M., Dillip, G. R., Kim, D. H., and Lee, Y. R. (2016). Toxicity and efficacy of CdO nanostructures on the MDCK and Caki-2 cells. J. Photochem. Photobiol. B 164, 174-181. doi: 10.1016/j.jphotobiol.2016.09.028

Stern, J. M., Stanfield, J., Kabbani, W., Hsieh, J. T., and Cadeddu, J. A. (2008). Selective prostate cancer thermal ablation with laser activated gold nanoshells. J. Urol. 179, 748-753. doi: 10.1016/j.juro.2007.09.018

Stern, J. M., Stanfield, J., Lotan, Y., Park, S., Hsieh, J. T., and Cadeddu, J. A. (2007). Efficacy of laser-activated gold nanoshells in ablating prostate cancer cells in vitro. J. Endourol. 21, 939-943. doi: 10.1089/end.2007.0437

Stone, L. (2016). Kidney cancer: exosome transmission of sunitinib resistance. Nat. Rev. Urol. 13:297. doi: 10.1038/nrurol.2016.88

Stuart, E. C., Scandlyn, M. J., and Rosengren, R. J. (2006). Role of epigallocatechin gallate (EGCG) in the treatment of breast and prostate cancer. Life Sci. 79, 2329-2336. doi: 10.1016/j.lfs.2006.07.036

Sudimack, J., and Lee, R. J. (2000). Targeted drug delivery via the folate receptor. Adv. Drug Deliv. Rev. 41, 147-162. doi: 10.1016/S0169-409X(99)00062-9
Sun, C., Lee, J. S., and Zhang, M. (2008). Magnetic nanoparticles in MR imaging and drug delivery. Adv. Drug Deliv. Rev. 60, 1252-1265. doi: 10.1016/j.addr. 2008.03.018

Tabatabaei, S., Harisinghani, M., and Mcdougal, W. S. (2005). Regional lymph node staging using lymphotropic nanoparticle enhanced magnetic resonance imaging with ferumoxtran-10 in patients with penile cancer. J. Urol. 174, 923-927. doi: 10.1097/01.ju.0000170234.14519.19

Thaxton, C. S., Elghanian, R., Thomas, A. D., Stoeva, S. I., Lee, J. S., Smith, N. D., et al. (2009). Nanoparticle-based bio-barcode assay redefines "undetectable" PSA and biochemical recurrence after radical prostatectomy. . Proc. Natl. Acad. Sci. U.S.A. 106, 18437-18442. doi: 10.1073/pnas.0904719106

Vila-Caballer, M., Codolo, G., Munari, F., Malfanti, A., Fassan, M., Rugge, M., et al. (2016). A pH-sensitive stearoyl-PEG-poly(methacryloyl sulfadimethoxine)decorated liposome system for protein delivery: an application for bladder cancer treatment. J. Control. Release 238, 31-42. doi: 10.1016/j.jconrel.2016. 07.024

Voruganti, S., Qin, J. J., Sarkar, S., Nag, S., Walbi, I. A., Wang, S., et al. (2015). Oral nano-delivery of anticancer ginsenoside 25-OCH3-PPD, a natural inhibitor of the MDM2 oncogene: nanoparticle preparation, characterization, in vitro and in vivo anti-prostate cancer activity, and mechanisms of action. Oncotarget 6 , 21379-21394. doi: 10.18632/oncotarget.4091

Wang, D., Fei, B., Halig, L. V., Qin, X., Hu, Z., Xu, H., et al. (2014). Targeted ironoxide nanoparticle for photodynamic therapy and imaging of head and neck cancer. ACS Nano 8, 6620-6632. doi: 10.1021/nn501652j

Wang, X., Yang, L., Chen, Z. G., and Shin, D. M. (2008). Application of nanotechnology in cancer therapy and imaging. CA Cancer J. Clin. 58, 97-110. doi: 10.3322/CA.2007.0003

Williams, R. M., Jaimes, E. A., and Heller, D. A. (2016). Nanomedicines for kidney diseases. Kidney Int. 90, 740-745. doi: 10.1016/j.kint.2016.03.041

Xu, K., Ding, Q., Fang, Z., Zheng, J., Gao, P., Lu, Y., et al. (2010). Silencing of HIF-1alpha suppresses tumorigenicity of renal cell carcinoma through induction of apoptosis. Cancer Gene Ther. 17, 212-222. doi: 10.1038/cgt. 2009.66

Yan, X., Al-Hayek, S., Huang, H., Zhu, Z., Zhu, W., and Guo, H. (2013). Photodynamic effect of 5-aminolevulinic acid-loaded nanoparticles on bladder cancer cells: a preliminary investigation. Scand. J. Urol. 47, 145-151. doi: 10.3109/00365599.2012.713000

Yang, Q., Wang, Y., Yang, Q., Gao, Y., Duan, X., Fu, Q., et al. (2017). Cuprous oxide nanoparticles trigger ER stress-induced apoptosis by regulating copper trafficking and overcoming resistance to sunitinib therapy in renal cancer. Biomaterials 146, 72-85. doi: 10.1016/j.biomaterials.2017. 09.008

Yang, X., Stein, E. W., Ashkenazi, S., and Wang, L. V. (2009). Nanoparticles for photoacoustic imaging. Wiley Interdiscip. Rev. Nanomed. Nanobiotechnol. 1, 360-368. doi: 10.1002/wnan.42

Yu, Z., Schmaltz, R. M., Bozeman, T. C., Paul, R., Rishel, M. J., Tsosie, K. S., et al. (2013). Selective tumor cell targeting by the disaccharide moiety of bleomycin. J. Am. Chem. Soc. 135, 2883-2886. doi: 10.1021/ja311090e

Yuan, Z. X., Mo, J., Zhao, G., Shu, G., Fu, H. L., and Zhao, W. (2016). Targeting strategies for renal cell carcinoma: from renal cancer cells to renal cancer stem cells. Front. Pharmacol. 7:423. doi: 10.3389/fphar.2016.00423

Zhang, T., Xue, X., He, D., and Hsieh, J. T. (2015). A prostate cancer-targeted polyarginine-disulfide linked PEI nanocarrier for delivery of microRNA. Cancer Lett. 365, 156-165. doi: 10.1016/j.canlet.2015.05.003

Zrazhevskiy, P., and Gao, X. (2013). Quantum dot imaging platform for single-cell molecular profiling. Nat. Commun. 4:1619. doi: 10.1038/ncomms2635

Conflict of Interest Statement: The authors declare that the research was conducted in the absence of any commercial or financial relationships that could be construed as a potential conflict of interest.

Copyright $\odot 2018$ He, Chen, Zheng, Tu, He, Fu, Lin, Zhang, Shu, He and Yuan. This is an open-access article distributed under the terms of the Creative Commons Attribution License (CC BY). The use, distribution or reproduction in other forums is permitted, provided the original author(s) and the copyright owner(s) are credited and that the original publication in this journal is cited, in accordance with accepted academic practice. No use, distribution or reproduction is permitted which does not comply with these terms. 